\title{
Kinin-B1 Receptors in Ischaemia-Induced Pancreatitis: Functional Importance and Cellular Localisation
}

\author{
Joachim F. Kuebler ${ }^{1}$, Elisabeth Schremmer- \\ Danninger ${ }^{2,3, a}$, Kanti D. Bhoola ${ }^{3, b}$, \\ Adelbert A. Roscher ${ }^{2}$, Konrad Messmer ${ }^{1}$ \\ and Tomas F. Hoffmann ${ }^{1, *}$ \\ ${ }^{1}$ Institute of Surgical Research, Großhadern Clinic, \\ Ludwig-Maximilians-University, Marchioninistraße 15, \\ D-81377 Munich, Germany \\ 2 Department of Clinical Biochemistry, Childrens \\ Hospital, Klinikum Innenstadt, Ludwig-Maximilians- \\ University, Lindwurmstraße 4, D-80337 Munich, \\ Germany \\ ${ }^{3}$ Department of Clinical and Experimental \\ Pharmacology, Nelson R. Mandela School of Medicine, \\ University of Natal, Private Bag 7, Congella 4013, \\ Durban, South Africa \\ ${ }^{*}$ Corresponding author
}

In this study we compare the role of kinin-B1 and B2 receptors during ischaemia/reperfusion of rat pancreas. Our investigations were prompted by the observation that infusion of a kinin-B2 receptor antagonist produced significant improvement in acute experimental pancreatitis. In an acute model with two hours of ischaemia/two hours of reperfusion, application of the kinin-B1 receptor antagonist (CP-0298) alone, or in combination with kinin-B2 receptor antagonist (CP-0597), significantly reduced the number of adherent leukocytes in post-capillary venules. In a chronic model with five days of reperfusion, the continuous application of kinin-B1 receptor antagonist or a combination of kinin-B1 and B2 receptor antagonists markedly reduced the survival rate. In kinin-receptor binding studies kinin-B1 receptor showed a 22-fold increase in expression during the time of ischaemia/reperfusion. Carboxypeptidase $M$ activity was up-regulated 10-fold following two hours of ischaemia and two hours of reperfusion, provided the appropriate specific ligand, des-Arg10-kallidin and/or des-Arg9-bradykinin, was used. The occurrence of kinin-B1 receptor binding sites on acinar cell membranes was demonstrated by micro-autoradiography. With a specific antibody, the localisation of kinin-B1

\footnotetext{
a Present address: Institute of Diabetes Research, Koelner Platz 1, D-80804 Munich, Germany

b Present address: Asthma and Allergy Research Institute, The University of Australia, Sir Charles Gairdner Hospital, Hospital Avenue, Nedlands WA 6009, Australia
}

receptor protein was confirmed at the same sites. In conclusion, we have demonstrated the up-regulation of the pancreatic acinar cell kinin-B1 receptors during ischaemia/reperfusion. The novel functional finding was that antagonism of the kinin-B1 receptors decreased the survival rate in an experimental model of pancreatitis.

Key words: Antagonists / Carboxypeptidase M/

Kinin-B1 receptor antibody/Microcirculation /

Rat pancreas/Receptor autoradiography.

\section{Introduction}

Evidence for the enhanced formation and release of kinin peptides in acute pancreatitis is well established (Griesbacher et al., 1993; Hoffmann et al., 1997). The kinin peptides are potent mediators of vasodilation, increased capillary permeability, oedema and pain (Bhoola et al., 1992). Furthermore, mild pancreatitis can be increased in severity by the continuous, intra-arterial infusion of bradykinin (Hoffmann et al., 1996a).

In mammals, the cellular actions of kinins are transducted by two receptors, the kinin-B1 receptor and kinin$\mathrm{B} 2$ receptor. Whereas the kinin-B2 receptor is constitutively expressed, the kinin-B1 receptor is induced by a variety of stimuli. Isolated large arterial preparations respond to the kinin-B1 receptor agonist, des-Arg'bradykinin (Regoli et al., 1977). Expression of kinin-B1 receptors is also increased by the infusion of bradykinin or by the inhibition of angiotensin-converting enzyme, kininase II (Nwator et al., 1989), probably as a positive feedback mechanism following the maximal activation of the kinin-B1 receptors expressed under normal conditions. Induction of kinin-B1 receptors is enhanced in inflamed organs, as has been observed in renal transplant rejection and parenchymal diseases (Bhoola et al., 2001). Additionally, ischaemia/reperfusion of the myocardium and endotoxin infusion subjected to piglets enhances the expression of kinin-B1 receptors (Schremmer-Danninger et al., 1998; Mazenot et al., 2001).

During ischaemia/reperfusion studies in experimental pancreatitis, antagonism of the kinin-B2 receptors has been shown to exhibit a protective effect (Closa et al., 1995; Hoffmann et al., 1996b,c, 1997; Kanbe et al., 1996). The question whether kinin-B1 receptors serve a functionally important role in pancreatitis has not been investigated. Therefore, one purpose of our study was to assess both the influence of a kinin-B1 receptor antagonist (CP 0298) alone, and in combination with a kinin-B2 receptor antagonist (CP 0597), by observing the microcirculation in 
an acute model, and mortality in a chronic model of pancreatitis. The second aim of our study was to localise and quantify the kinin-B1 receptor, and to determine the enzymatic activity of carboxypeptidase $\mathrm{M}$ activity, providing the kinin-B1 receptor ligand in the acute model.

\section{Results}

\section{Acute Mode}

Survival All sham-operated animals survived the observation period of $2.5 \mathrm{~h}$. One animal of the ischaemia/ reperfusion control group, 6 animals of the kinin-B1 receptor antagonist group, and 4 rats of the combined kinin-B1 and B2 receptor antagonists group, died within the reperfusion period of $2.5 \mathrm{~h}$, but after the registered observation time of 120 min. $n=7$ in each group.

Blood Gases During the experiment $\mathrm{pCO}_{2}$ and $\mathrm{pO}_{2}$ were kept constant in all groups. The $\mathrm{pH}$ decreased slightly from a mean of $7.39 \pm 0.02$ at the beginning of the experiment to $7.35 \pm 0.02$ at the end. In all four groups the base excess decreased continuously from a baseline of $-1.54 \pm 0.71 \mathrm{~mm}$ to $-5.63 \pm 0.96 \mathrm{~mm}$ after $2 \mathrm{~h}$ of reperfusion. Within these parameters no significant difference was observed at the equivalent time-points between the groups.

Macro-Haemodynamic Parameters In sham-operated animals the mean arterial pressure (MAP) showed no major changes during the time of experiment. All groups made ischaemic showed a significant drop in blood pressure after the onset of reperfusion (Figure 1A). In the sham group, the central venous pressure (CVP) remained almost stable during the experimental period. In groups 3 and 4 (involving kinin antagonists) there was a continuous decrease of CVP during the observed reperfusion period. At 30 min of reperfusion, the ischaemia/reperfusion control group showed a significant fall in CVP compared to the antagonism groups, which remained at that level during the time of the experiment (Figure 1B). The heart rate (HR) did not significantly change between the groups (not shown).

Haematocrit At the beginning of each experiment the haematocrit of all groups was $41 \pm 2.1 \%$. There was no appreciable change of haematocrit after the time of ischaemia. At 30 min of reperfusion, the haematocrit of the ischaemia/reperfusion control group without treatment with antagonists (group 2), when compared to the other groups, was significantly elevated to a mean value of $48.3 \pm 2.63 \%$. At $60 \mathrm{~min}$ and $120 \mathrm{~min}$ of reperfusion, the haematocrit of the antagonist-treated groups 3 and 4 was also increased. Only the haematocrit of the sham group (group 1) remained virtually unchanged, and at these time-points was significantly lower than the haematocrit of all the other groups (Figure 2A).

The peripheral leukocyte count decreased slightly in all

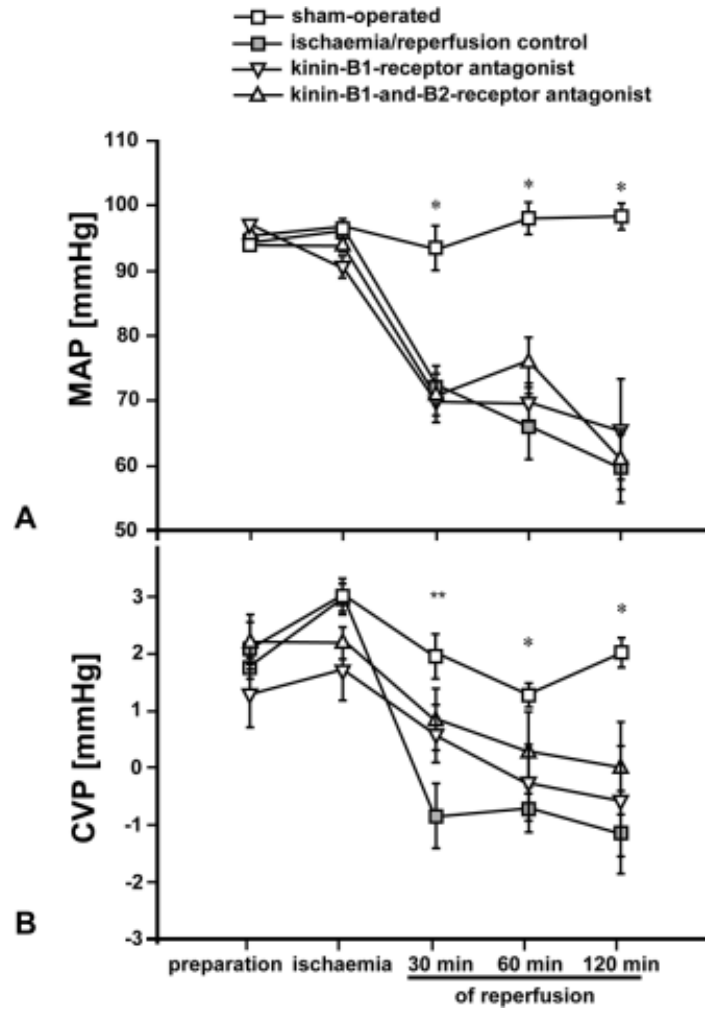

Fig. 1 Acute Model: Mean Arterial Pressure and Central Venous Pressure.

$\mathrm{n}=7$ in each group; group 1: sham-operated, group 2: ischaemia/reperfusion control, group 3: kinin-B1 receptor antagonist, group 4: kinin-B1 and B2 receptor antagonists. Time points show values at the end of preparation, end of ischaemia ( $2 \mathrm{~h}$ ), after $30 \mathrm{~min}, 60 \mathrm{~min}$ and $120 \mathrm{~min}$ of reperfusion; values represent means \pm SEM. ${ }^{*} p<0.05$ vs. ischaemia/reperfusion control, kininB1 receptor antagonist and kinin-B1 and -B2 receptor antagonists (Student-Newman-Keul test). For details see Materials and Methods.

(A) Changes of mean arterial pressure (MAP). Animals of all groups made ischaemic showed a significant drop in blood pressure after onset of reperfusion. (B) Changes of central venous pressure (CVP). Rats of antagonist-treated groups 3 and 4 showed a continuous fall, group 2 showed a significant drop after the onset of reperfusion.

${ }^{* *} p<0.05$ vs. ischaemia/reperfusion control and kinin-B1 receptor antagonist (Student-Newman-Keul test).

groups (basal $9.3 \pm 2.3$ leukocytes $/ \mathrm{mm}^{2}$, at the end $6.6 \pm 1.4$ leukocytes $/ \mathrm{mm}^{2}$ ), with no significant difference between the groups (not shown).

Micro-Haemodynamic Parameters In all groups with experimentally-induced ischaemia, the functional capillary density (FCD) was significantly reduced compared to the sham group (Figure 2B). During the reperfusion period, the number of perfused capillaries decreased further, widening the gap relevant to the sham group. Between antagonist-treated groups 3 and 4, and not antagonisttreated group 2, as well as between the two antagonisttreated groups, there was no significant difference at any of the observation time-points. 
A
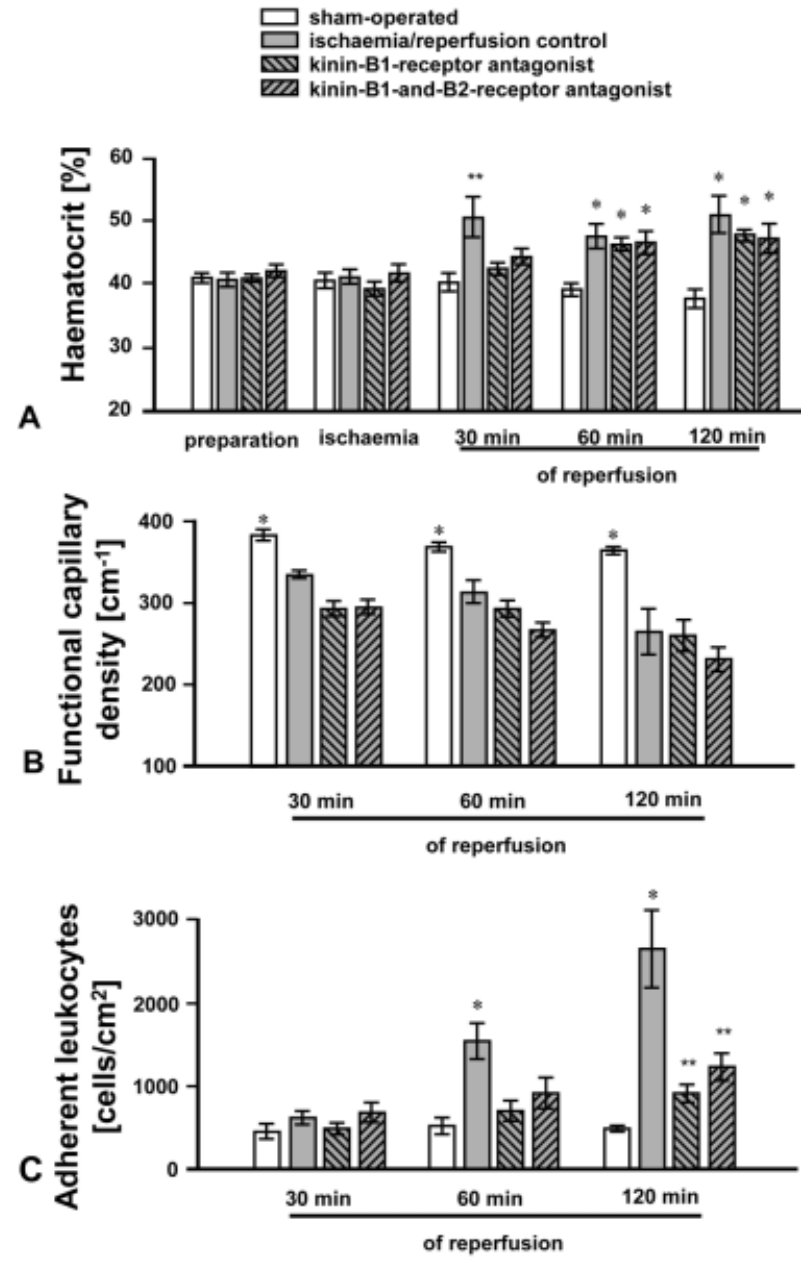

Fig. 2 Acute Model: Haematocrit, Functional Capillary Density and Adherent Leukocytes (see Material and Methods).

$\mathrm{n}=7$ in each group; group 1: sham-operated, group 2: ischaemia/reperfusion control, group 3: kinin-B1 receptor antagonist, group 4: kinin-B1 and B2 receptor antagonists. Time points show values at the end of preparation, end of ischaemia ( $2 \mathrm{~h}$ ), after $30 \mathrm{~min}, 60 \mathrm{~min}$ and $120 \mathrm{~min}$ of reperfusion; values represent mean \pm SEM.

(A) Changes of haematocrit - during the reperfusion time the haematocrit of the ischaemic groups rose, significantly for group 2. ${ }^{*} p<0.05 v s$. sham-operated, kinin-B1 receptor antagonist and kinin-B1 and B2 receptor antagonists. ${ }^{* \star} p<0.05$ vs. ischaemia/reperfusion control, kinin-B1 receptor antagonist and kinin-B1 and B2 receptor antagonists (Student-NewmanKeul test). (B) Functional capillary density (FCD), given as the length of red blood cell-perfused capillaries per observation area $\left(\mathrm{cm} / \mathrm{cm}^{2}\right)$, ischaemia/reperfusion injury induced significantly capillary 'no-reflow' compared to the sham-operated group and was worsened over time. ${ }^{*} p<0.05 \mathrm{vs}$. ischaemia control, kinin-B1 receptor antagonist and kinin-B1 and B2 receptor antagonists (Student-Newman-Keul test). (C) Number of adherent leukocytes in at least 3 post-capillary venules. The ischaemia/reperfusion control group showed a significant rise in the count of stickers, antagonist-treated rats showed a much lesser increase. ${ }^{*} p<0.05$ vs. sham, kinin-B1 receptor antagonist and kinin-B1 and B2 receptor antagonists. ${ }^{* *} p<0.05$ vs. sham-operated and ischaemia control (Student-NewmanKeul test).
The fraction of rolling leukocytes did not significantly differ among all of the groups $\left(29.4 \pm 4.7\right.$ cells $/ \mathrm{mm}^{2}$ at $30 \mathrm{~min}, 31.0 \pm 5.5 \mathrm{cell} / \mathrm{mm}^{2}$ at $120 \mathrm{~min}$ ). The number of adherent leukocytes (stickers) stayed constant in the sham group (Figure 2C). However, the ischaemia control group showed a substantial increase of so-called stickers during the period of observation: Until $30 \mathrm{~min}$, the amount of stickers remained the same as for the sham group, whereas at 60 and $120 \mathrm{~min}$ after onset of ischaemia the number was significantly greater than that of the other groups (Figure 2C). In the antagonist-treated animals of groups 3 and 4, the accumulation of leukocytes at 30 min was nearly the same as in sham-operated rats, but at 60 and 120 min significantly higher. There were no significant differences between the two antagonist-treated groups (Figure 2C).

Morphology Histology of pancreatic tissue revealed no apparent sign of tissue damage or inflammatory process in biopsies obtained from sham-operated animals. The pancreatic tissue harvested from all animals subjected to ischaemia and reperfusion, regardless of treatment, showed areas with distinct oedema, necrotic areas and signs of inflammation.

\section{Chronic Model}

In the sham group (group I) all rats survived the observation period of 5 days. In the ischaemia/reperfusion group (group II), four of the six animals survived, resulting in a survival rate of $67 \%$. None of the animals receiving the kinin-B1 receptor antagonist (group III) survived, and in the kinin-B1 and B2 receptor antagonism group (group IV) only one rat survived 5 days following ischaemia, giving a survival rate of $16.7 \%$. All but one of the kinin-B1 receptor antagonist-treated animals died within the first two days. $n=6$ for all groups, for the sham group: $n=4$.

The amylase levels in the ischaemia control group (group II) rose to a maximum of $4454 \pm 986 \mathrm{U} / \mathrm{I}$ on the first day after ischaemia, then decreased to $1711 \pm 658 \mathrm{U} / \mathrm{l}$ on the fifth day following ischaemia. In the sham group (group I) the levels were $1875 \pm 544 \mathrm{U} / \mathrm{l}$ on the first day and $1683 \pm 725 \mathrm{U} / \mathrm{I}$ on the fifth.

The levels of blood glucose $(106 \pm 13 \mathrm{mg} / \mathrm{dl})$ remained stable and were not affected by the sham operation or by ischaemia/reperfusion.

The number of peripheral leukocytes in the ischaemia/ reperfusion group (group II) increased from $(12.4 \pm 3.5) \times$ $10^{12} \mathrm{I}^{-1}$ cells $/ \mathrm{mm}^{2}$ after ischaemia to $(17.2 \pm 5.2) \times 10^{12} \mathrm{I}^{-1}$ cells $/ \mathrm{mm}^{2}$ after five days of reperfusion. In the sham group (group I) the numbers were $(14.6 \pm 2.7) \times 10^{12} \mathrm{I}^{-1}$ cells $/ \mathrm{mm}^{2}$ after sham operation and $(12.2 \pm 5.2) \times 10^{12} \mathrm{I}^{-1}$ cells $/ \mathrm{mm}^{2}$ after five days.

\section{Carboxypeptidase M}

Carboxypeptidase $\mathrm{M}$ activity, providing the appropriate kinin-B1 receptor ligand, was elevated approximately 4-fold above control in ischaemic pancreatic tissue and 
10-fold in ischaemic and reperfused tissues. Figure 3 shows the mean \pm SEM from three different experiments in duplicate determinations.

\section{Binding Studies and Receptor Micro-Autoradiography}

Receptor binding studies revealed changes in kinin-B1 receptor binding during ischaemia/reperfusion of rat

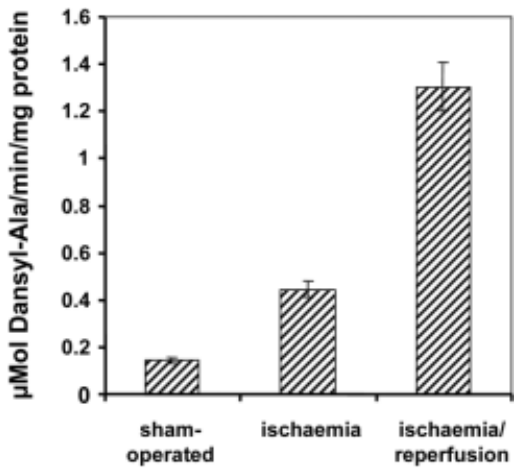

Fig. 3 Carboxypeptidase M Up-Regulation.

Carboxypeptidase $\mathrm{M}$ activity was evaluated in tissue homogenates from control, ischaemic and ischemia/reperfusion rat pancreas as described by Tan et al. (1995). Values represent mean \pm SEM of duplicate determinations. A massive increase of carboxypeptidase $\mathrm{M}$ activity during ischaemia and ischaemia/ reperfusion processes could be evaluated.

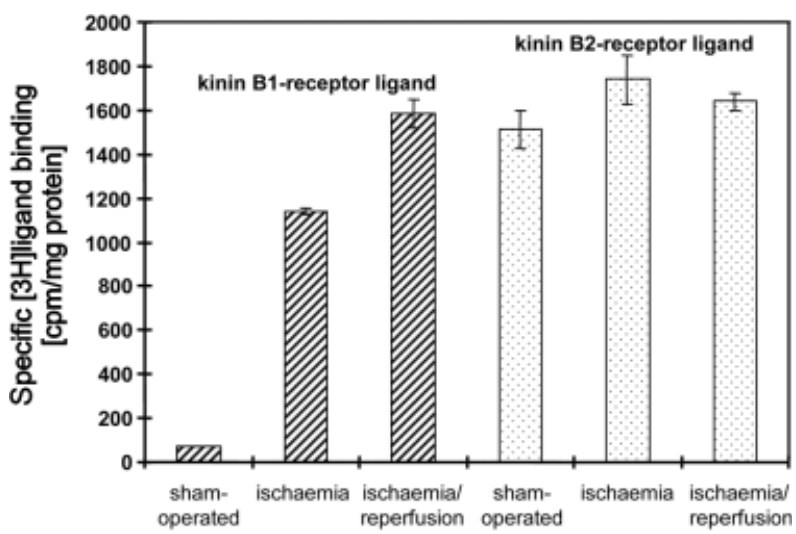

Fig. 4 Kinin-B1 and B2 Receptor Binding Studies.

Pancreatic cryosections were obtained from the sham-operated group, ischaemia group and ischaemia/reperfusion group. Subsequent to association with a saturating concentration of $\left[{ }^{3} \mathrm{H}\right]$ des-Arg10-kallidin $(4 \mathrm{~nm})$ or $\left[{ }^{3} \mathrm{H}\right]$ bradykinin $(3.8 \mathrm{~nm})$ in the presence (unspecific binding) or absence (total binding) of an excess $(1 \mu \mathrm{M})$ of unlabelled ligand (according to the method described by Schremmer-Danninger et al., 1995), the binding reaction was terminated. Sections were then wiped off with filter paper and placed into scintillation vials for assessment of specific binding that is calculated as the difference between total and unspecific binding. Values represent mean \pm SEM of triplicate determinations. For kinin-B2 receptors, no significant changes in specific binding were observed, whereas a dramatic rise in kinin-B1 receptor ligand binding could be demonstrated.
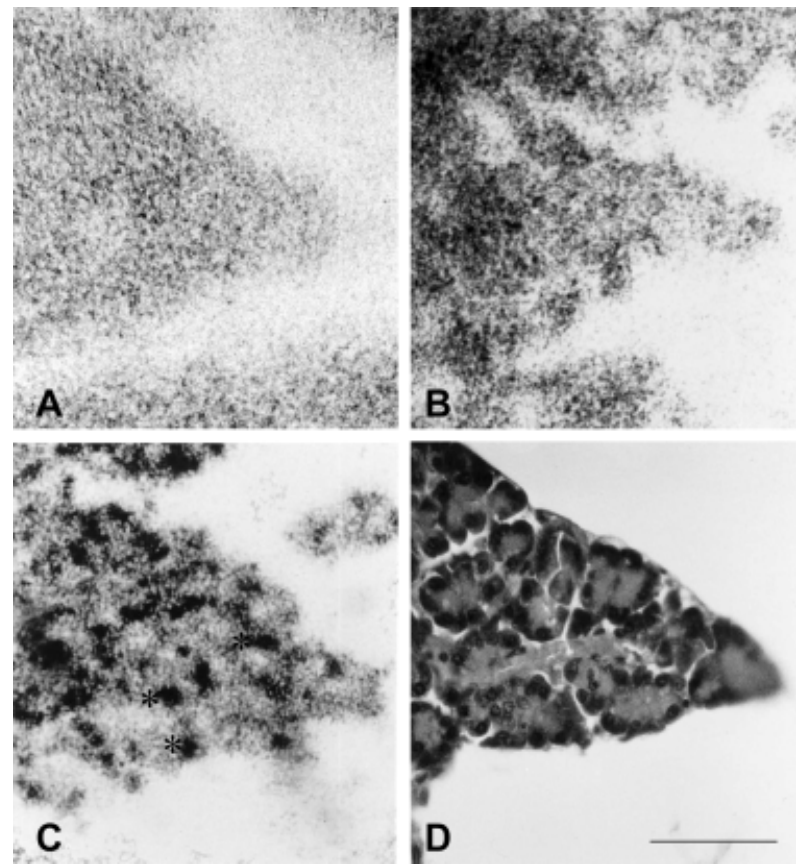

Fig. 5 Emulsion Micro-Autoradiographs of Kinin-B1 Receptors on Pancreatic Lobes.

Incubation of pancreatic cryosections with $\left[{ }^{3} \mathrm{H}\right]$ des-Arg10Kallidin (4 nM) as described in Material and Methods. (A) Control: Above cryosections of control tissue, receptor micro-autoradiography using emulsion-coated coverslips displayed only diffusely scattered silver grains with no preference for a distinct tissue structure. (B) Ischaemia for $2 \mathrm{~h}$ : on coverslips above pancreatic tissue derived from ischaemic pancreas the arrangement of silver grains shows a beginning of clustering. (C) Ischaemia for $2 \mathrm{~h}$ and reperfusion for $2 \mathrm{~h}$ : the distribution of silver grains above ischaemia/reperfusion tissues is restricted to acini. Dark clusters of silver grains represent total $\left[{ }^{3} \mathrm{H}\right]$ des-Arg10Kallidin binding to distinct acini $\left(^{*}\right)$. (D) Histology (haematoxylineosin) of a pancreatic lobe of control. Scale bar $=100 \mu \mathrm{m}$.

pancreas. Pancreatic cryosections were incubated as described under Material and Methods. For ischaemic tissue, kinin-B1 receptor binding was almost 16-fold greater than the control value, and for pancreatic tissue obtained from animals receiving $2 \mathrm{~h}$ reperfusion after $2 \mathrm{~h}$ of ischaemia, the increase was 22-fold (Figure 4). For kinin-B2 receptor binding, no significant changes were observed (Figure 4).

High resolution receptor micro-autoradiography using emulsion-coated coverslips, when displayed above the cryosections of control tissue, showed only diffusely scattered silver grains with no preference for any distinct tissue structure (Figure 5A). On coverslips placed above pancreatic tissue derived from ischaemic pancreas, the arrangement of silver grains showed the beginning of clustering (Figure 5B). The distribution of silver grains on coverslips placed above ischaemia/reperfusion tissues was restricted to acini. Dark clusters of silver grains represented specific $\left[{ }^{3} \mathrm{H}\right]$ des-Arg10-kallidin binding to distinct acini (Figure 5C).

Quantitation of $\left[{ }^{3} \mathrm{H}\right]$ des-Arg10-kallidin binding to rat 
pancreatic acinar cells on kinin-receptor micro-autoradiographs, obtained by automated image analysis of silver grain density above single acinar cells, showed an approximate 10-fold greater degree of binding for ischaemic tissue, and a 17-fold greater binding to pancreatic tissue subjected to $2 \mathrm{~h}$ of ischaemia and $2 \mathrm{~h}$ of reperfusion. This quantitation of $\left[{ }^{3} \mathrm{H}\right]$ des-Arg10-kallidin is shown as an area of particles in percent of total area predefined \pm SEM and revealed for pancreatic cryosections from the sham-operated group $4.7 \pm 0.84$, from the ischaemia group $46 \pm 2.8$ and from the ischaemia/reperfusion group 78.2 \pm 3.5 .

In Figure 5D, the staining with haematoxylin and eosin illustrates the acinar areas of a pancreatic lobe of a shamoperated rat.

\section{Specific Kinin-B1 Receptor Antibody}

As demonstrated by receptor micro-autoradiography, clusters of kinin-B1 receptors were located on acini. The $\left[{ }^{3} \mathrm{H}\right]$-labelled specific ligand bound specifically to acini in pancreatic tissue with $2 \mathrm{~h}$ of ischaemia and $2 \mathrm{~h}$ of reperfusion. With the method of immunocytochemistry it could be evaluated that at identical sites at which the specific kinin-B1 receptor ligand bound, polyclonal anti-kinin-B1 receptor antibody also reacted with specific staining. Method controls (replacement of primary antibody by buffer or non-immune serum) and tissue controls (shamoperated pancreas) did not reveal staining (not shown).

\section{Discussion}

A critical factor in the development and progressive severity of acute pancreatitis is the degree of microcirculatory flow (Klar et al., 1990; Bassi et al., 1994). Failure in nutritive perfusion causes focal hypoxia and cellular damage, which in turn hinders reperfusion of the pancreatitis tissue. One reason for the reduction in microcirculatory flow during acute pancreatitis may be the local formation of kinins by tissue and/or plasma kallikreins. Kinins, by increasing the permeability of vessel wall, produce extensive oedema and damage to the pancreatic cells (Griesbacher et al., 1993; Hirata et al., 2002). In vessels with damaged endothelium, kinins act as vasoconstrictors, thus further decreasing perfusion of the ischaemic areas (Pruneau et al., 1994). Both actions contribute to a negative effect on microcirculation.

The cellular actions of kinins are mediated by two receptors, the kinin-B1 and B2 receptors. These receptors activate cells through similar, but not identical, signalling pathways (Marceau et al., 1997). They differ in tachyphylaxis (Austin et al., 1997), and the manner of expression. In humans, although their gene sequences have a homology of about $36 \%$ (Hall et al., 1997), they serve both similar and contrasting functional responses (Regoli et al., 1997), as observed in experiments involving the kinin-B1 and $\mathrm{B} 2$ receptor blockade. In a model of porcine endotoxin shock, the antagonism of kinin-B1 receptors pro- duced functional effects opposite to those observed with kinin-B2 receptor antagonists (Siebeck et al., 1996). Kinin-B1, in contrast to B2 receptor antagonist, does not inhibit the catecholamine production of neural cells, but seems to have an agonistic effect similar to that of bradykinin (Dendorfer et al., 1996). When endothelial lesions occur, the release of proteinases causes activation of the coagulation cascade, which contributes to the failure of the microcirculation in acute pancreatitis. The activation of platelets, an important step in coagulation, is also influenced by kinin-B1 receptor antagonism. Furthermore, the application of a selective kinin-B2 receptor antagonist was shown to have a protective effect on the pancreas in different models of acute pancreatitis (Griesbacher et al., 1995; Kanbe et al., 1996; Asano et al., 1997; Hoffmann et al., 1997; Bloechle et al., 1998). There was an improvement in the microcirculation, less oedema, the amylase levels within the pancreas were reduced, and the survival rate increased.

This study reports a novel action of the kinin-B1 receptor antagonist in experimental pancreatitis. In the acute model, microcirculatory parameters were assessed following $2 \mathrm{~h}$ of ischaemia and $2 \mathrm{~h}$ of reperfusion. The selective kinin-B1 receptor antagonist, as well as the combined kinin-B1 and B2 receptor antagonists, decreased the functional capillary density significantly. So, in contrast to the selective kinin-B2 receptor antagonism, shown by Hoffmann et al. (1996b,c), the nutritive perfusion of the pancreas was reduced by the application of a kinin-B1 receptor antagonist. The post-ischaemic increase of the adherent leukocytes, however, was reduced in all antagonist-treated groups. Usually the number of adherent leukocytes is correlated with the degree of tissue damage and with microcirculatory failure. The adhesion of numerous leukocytes, mainly polymorphonuclear granulocytes, to the endothelial cells of the post-capillary venules further denotes the presence of inflammation. The release of metabolites by activated leukocytes also contributes to the ischaemia/reperfusion injury. In our study the leukocyte-endothelium interaction seemed to be positively influenced by the kinin-B1 receptor antagonist, and in this regard agrees with observations by Ahluwalia et al. (1996), who have shown that the accumulation of polymorphonuclear leukocytes in air pouches of mice is inhibited by antagonism of kinin-B1, but not the B2, receptors. The activation of polymorphonuclear leukocytes by kinin-B1 receptor ligand has also been reported (Carl et al., 1996).

Our experiments demonstrate that the application of the kinin-B1 receptor antagonist, CP-0298, during ischaemically-induced pancreatitis aggravated the course of acute pancreatitis. Moreover, in contrast to protective effects observed by our group and others in previous studies using only a kinin-B2 receptor antagonist, we observed that the combined kinin B1 and B2 receptor antagonists did not show any beneficial effects (Hoffmann et al., 1996c; Kanbe et al., 1996). This deleterious effect was independent of the significantly reduced leukocyteendothelium interaction. 
In our chronic model with five days of reperfusion, the survival rate decreased drastically upon treatment with the kinin-B1 receptor antagonist alone or in combination with the kinin-B2 receptor antagonist. Versus the vehicle treated group, a statistically significant difference in the survival time could be seen. All but one animal died within the first two days.

Furthermore, we included only animals that survived the initial reperfusion period and completely awoke after anaesthesia to minimize the variation caused by the ether anaesthesia on the outcome. We observed that in the kinin-B1 receptor antagonist treated animals, in addition to the six animals included in the study, another seven animals had to be excluded and in the combined treatment group five animals died in the early resuscitation period, whereas only one vehicle-treated animal had to be excluded. Moreover, in the chronic model, animals were observed for several days following the induction of acute necrotizing pancreatitis without any pain medication or any form of anaesthesia. Therefore, as soon as there were sufficient data to show that kinin-B1 antagonism would not benefit patients suffering from acute pancreatitis, either alone or in combination with kinin-B2 receptor antagonism, we stopped the experiments. It should also be noted that several authors have described a survival benefit of kinin-B2 receptor antagonism in models of acute pancreatitis (Kanbe et al., 1996; Satake et al., 1996; Yekebas et al., 2000). In our experiments the combined antagonism of both kinin receptors not only did not show any beneficial effects, but in fact decreased the survival rate.

This up-regulation of kinin-B1 receptor along with increased carboxypeptidase M activity in the ischaemic and reperfused tissue may represent an important physiological mechanism protecting from the damaging effects of pancreatic injury. Not only kinin-B2 receptor antagonists, but also kinin-B1 receptor agonists, may be protective in acute pancreatitis. Physiologically, carboxypeptidase $M$ turns the kinin-B2 receptor ligand bradykinin into an excellent kinin-B1 receptor agonist that no longer exhibits high affinity for the kinin-B2 receptor. The elevated activity of carboxypeptidase $\mathrm{M}$ leads to an elevated amount of kinin-B1 receptor agonist. Up-regulation of kinin-B1 receptor can show its effects only if enough specific agonist is available.

Further studies are now necessary to clarify the molecular mechanisms responsible for the detrimental effect of the kinin-B1 receptor antagonist.

\section{Materials and Methods}

\section{Acute Model}

The current study was designed using the recently described ischaemia/reperfusion model of acute pancreatitis (Hoffman et al., 1995) with minor modifications. The experiments were performed on 35 male Sprague-Dawley rats (Charles River, Sulzfeld, Germany), weighing 180-250 g. Anaesthesia was induced by ether inhalation following intraperitoneal application of chlo- ralhydrate $(250 \mathrm{mg} / \mathrm{kg}$ body weight, i.p. as bolus injection) and maintained by intravenous infusion of $\alpha$-chloralose (approximately $20 \mathrm{mg} / \mathrm{kg}$ body weight per hour, i.v.). The rats were placed on a heating plate and body temperature was kept at $36.5^{\circ} \mathrm{C}\left( \pm 0.5^{\circ} \mathrm{C}\right)$. After tracheotomy, the animals were mechanically ventilated (arterial $\mathrm{pO}_{2}: 100-110 \mathrm{~mm} \mathrm{Hg}$, arterial $\mathrm{pCO}_{2}$ : 35-40 mm Hg). Polyethylene catheters (PE50, 0.58 ID, 0.96 OD, Portex, Hythe, Kent, UK) were placed into the right common carotid artery and jugular vein and connected to pressure transducers. The abdomen was transversely opened, the short gastric arteries ligated and dissected, and the greater omentum removed from the greater curvature of the stomach. Once the surgical preparation was completed, the animals were allowed to stabilise for $30 \mathrm{~min}$. To create complete and reversible ischaemia of the pancreas, the four supplying arteries (gastroduodenal artery, left artery, splenic artery and caudal pancreaticoduodenal artery) were occluded with microvascular clips (Aesculap-Yasargil-Standard-Aneurysm-Clip Temporary, cat. no. FE $751 \mathrm{~K}$, closing force $70 \mathrm{~g}$, Aesculap, Tuttlingen, Germany). After $2 \mathrm{~h}$ of ischaemia, the clips were removed and the pancreas in situ carefully positioned on a stage for quantitative analysis of microcirculation, including functional capillary density and leukocyte-endothelium interaction by intravital fluorescence microscopy. Fifteen minutes before onset of reperfusion the continuous infusion of the respective drug was started. The osmotic minipump (Alzet Model 2001, Alza Corporation, Palo Alto, USA) was filled with phosphate buffer $(0.01 \mathrm{M}, \mathrm{pH} 7.4)$ or antagonists (dissolved in phosphate buffer) (antagonists provided by Cortech, Inc., Denver, USA) and placed intraperitoneally. Tissue samples from the body of the pancreas were taken $2.5 \mathrm{~h}$ after onset of reperfusion and after fixation stained with haematoxylin and eosin for histological examination.

The macro-haemodynamic parameters, mean arterial pressure (MAP), heart rate (HR) and central venous pressure (CVP), were monitored continuously during the entire experiment. The systemic haematocrit was assessed at the beginning and at the end of each experiment, and also at the end of ischaemia. At the beginning and at the end of the experiment, the peripheral leukocyte cell count was determined using a Coulter Counter T540 (Coulter Electronics, Hialeah, USA).

The experimental protocol for the acute study comprises four groups of seven animals in each group $(n=7)$ :

Group 1: sham. Animals underwent sham operation without vessel occlusion, the osmotic minipump was filled with $(0.9 \%$ $\mathrm{v} / \mathrm{v}$ ) sodium saline solution. The animals received $2 \mathrm{ml} / \mathrm{h}$.

Group 2: ischaemia/reperfusion control. Rats received $2 \mathrm{~h}$ of ischaemia and infusion $(2 \mathrm{ml} / \mathrm{h}$ ) of phosphate buffer.

Group 3: kinin-B1 receptor antagonist. Animals received $2 \mathrm{~h}$ of ischaemia and infusion $(2 \mathrm{ml} / \mathrm{h}$ ) of the selective kinin-B1 receptor antagonist CP-0298 at a concentration of $18 \mu \mathrm{g} \mathrm{kg}^{-1} \mathrm{~h}^{-1}$ dissolved in phosphate buffer.

Group 4: kinin-B1 and B2 receptor antagonists. Rats received $2 \mathrm{~h}$ of ischaemia and infusion $(2 \mathrm{ml} / \mathrm{h}$ each) of CP-0298 $(18 \mu \mathrm{g}$ $\left.\mathrm{kg}^{-1} \mathrm{~h}^{-1}\right)$, a selective kinin-B1 receptor antagonist and CP-0597 $\left(18 \mu \mathrm{kg}^{-1} \mathrm{~h}^{-1}\right)$, a selective kinin-B2 receptor antagonist, given by two different minipumps.

Animals with any sign of pancreatic oedema or haemorrhage, or a mean arterial blood pressure of less than $90 \mathrm{~mm} \mathrm{Hg}$ at the beginning of ischaemia, e.g. with signs of tissue damage or systemic stress caused by the preparation, were immediately sacrificed. Animals, that did not survive $2.5 \mathrm{~h}$ reperfusion are listed in the results section, but were not counted toward the seven animals per group. 


\section{Microcirculatory Studies}

The microcirculation was assessed by intravital microscopy at $30 \mathrm{~min}, 60 \mathrm{~min}$ and $120 \mathrm{~min}$ after inset of reperfusion. To enhance the contrast of the microvessels, $0.1 \mathrm{ml}$ of $0.75 \%(\mathrm{v} / \mathrm{w})$ fluorescein isothiocyanate-labelled hydroxyethyl starch (FITC-HAES, Laevosan, Linz, Austria) was intravenously injected before each period of microscopy. Leukocytes were stained in vivo by intravenous application of $0.1 \mathrm{ml} 0.2 \%(\mathrm{v} / \mathrm{w})$ rhodamine $6 \mathrm{G}$ (Sigma, St. Louis, USA). A saltwater immersion objective (SW 25/0.60, Leitz, Wetzlar, Germany) was used to achieve a magnification of about 800 fold. For off-line evaluation, images were stored on videotape (video recorder AG-7330, Panasonic, Munich, Germany).

The functional capillary density (FCD) of the pancreas was assessed after injection of FITC-HAES in ten randomly selected areas. It is defined as the length (cm) of erythrocyte-perfused capillaries per observation area $\left(\mathrm{cm}^{2}\right)$. Following the method described by Schmid-Schoenbein et al. (1977), the number of intersections between perfused capillaries and a grid system superimposed on a video screen was counted and the capillary length per observation area calculated.

The leukocyte-endothelial interaction was evaluated in three selected post-capillary venules with a diameter of 15 to $40 \mu \mathrm{m}$ and more than $100 \mu \mathrm{m}$ length. Non-adherent leukocytes were defined as cells freely flowing within the blood stream, with no interaction with the endothelium during the $30 \mathrm{~s}$ of observation period. Rolling leukocytes were defined as cells intermittently interacting with the endothelium for less than $30 \mathrm{~s}$. Adherent leukocytes (stickers) were defined as leukocytes attached to the inner vessel surface for the entire observation period of $30 \mathrm{~s}$, and are expressed as the number of cells per endothelial surface area $\left(\mathrm{mm}^{2}\right)$. The surface area was calculated assuming a cylindrical geometry of the vessel using diameter and length of the observed segment. The leukocyte flux was determined as the number of leukocytes passing the segment per second.

\section{Chronic Model with Five-Day Reperfusion}

Twenty-two male Sprague-Dawley rats (body weight 180-240 g) were used. Surgical anaesthesia was induced and maintained with vapourised ether inhaled by the spontaneously breathing animals. For volume replacement $(3 \mathrm{ml} 0.9 \% \mathrm{NaCl} / \mathrm{h})$, and for taking blood samples the right jugular vein was canulated with polyethylene tubes. After medial laparotomy and ligation of the short gastric arteries, the four supplying arteries of the pancreas were prepared and occluded for $2 \mathrm{~h}$ using microvascular clips. After $105 \mathrm{~min}$ (15 min before onset of reperfusion) one or two osmotic minipumps (Alzet Model 2001, Alza Corporation) filled with the respective drug were placed into the lower abdomen, and continuous perfusion $(1.06 \mu \mathrm{l} / \mathrm{h})$ of the peritoneum commenced. After removing the microvascular clips, the abdomen was closed by a trilaminar suture. The catheter was led subcutaneously to the neck and between the ears through the skin. It was fixed by a tobacco bag and raised three centimetres above skin level using a titan clip (Endo Clip II MI, Auto Suture, Tönisvorst, Sweden). The ether inhalation was stopped, and when the animals gained consciousness they were given free access to water and food. Each day, after $2 \mathrm{~h}$ of fasting, blood samples $(0.6 \mathrm{ml})$ were taken to assess the serum pancreatic amylase levels, using the P-amyl MPR 2 test (Boehringer, Mannheim, Germany) and fasting blood sugar levels. After five days of reperfusion the animals were killed by infusion of $\mathrm{KCl}$ through the catheter.

The experimental protocol for the chronic study comprised four to six animals in each group (antagonists provided by Cortech, Inc., Denver, USA).

Group I: sham $(n=4)$. Animals were sham-operated and their abdomens left open for $2 \mathrm{~h}$.
Group II: ischaemia/reperfusion control $(n=6)$. Animals underwent $2 \mathrm{~h}$ of ischaemia, 15 min before the end of ischaemia a minipump, filled with phosphate buffered saline, was placed into their abdomens and release was started.

Group III: kinin-B1 receptor antagonist $(n=6)$. Rats received $2 \mathrm{~h}$ of ischemia and infusion of CP-0298 $\left(18 \mu \mathrm{g} \mathrm{kg}^{-1} \mathrm{~h}^{-1}\right)$.

Group IV: combined kinin-B2 and B1 receptor antagonists $(\mathrm{n}=6)$. Rats received $2 \mathrm{~h}$ of ischaemia and infusion of CP-0298 $\left(18 \mu \mathrm{kg}^{-1} \mathrm{~h}^{-1}\right)$ and CP-0597 $\left(18 \mu \mathrm{gg}^{-1} \mathrm{~h}^{-1}\right)$.

\section{Receptor Binding Studies}

For receptor binding studies and autoradiographic staining of the kinin receptors the pancreas was removed before ischaemia (control group), after $2 \mathrm{~h}$ of ischaemia (ischaemia group), and after $2 \mathrm{~h}$ of ischemia and $2 \mathrm{~h}$ of reperfusion (ischaemia/reperfusion group). Tissue was washed in phosphate buffered saline $(0.01 \mathrm{M}, \mathrm{pH} 7.4)$ and immediately frozen in liquid nitrogen and stored at $-80^{\circ} \mathrm{C}$.

Cryosections were incubated, according to the method described by Schremmer-Danninger et al. (1995) for $2 \mathrm{~h}$ in an ice bath in $25 \mathrm{~mm}$ TES buffer (pH 6.8) sucrose $300 \mathrm{~mm}$, BSA $2 \%$, DTT $1 \mathrm{mM}$, supplemented with a protease inhibitor mixture consisting of bacitracin $2 \mathrm{~mm}, 1.10$-phenanthroline $1 \mu \mathrm{M}$, captopril $10 \mu \mathrm{M}$, phosphoramidon $10 \mu \mathrm{M}$. In kinin-B2 receptor studies 4.5 nM Mergetpa, a specific carboxypeptidase M inhibitor, was included in the protease inhibitor mixture. Binding studies were carried out by addition of nearly saturating concentrations of $3.8 \mathrm{~nm}\left[{ }^{3} \mathrm{H}\right]$ bradykinin (specific activity: $108 \mathrm{Ci} / \mathrm{mmol}$ ) or $4 \mathrm{nM}$ [ $\left.{ }^{3} \mathrm{H}\right]$ des-Arg10-kallidin (specific activity: $98 \mathrm{Ci} / \mathrm{mmol}$ ) as kinin-B2 and B1 receptor agonists in the presence (non-specific binding) or absence (total binding) of $1 \mu \mathrm{M}$ unlabelled agonist. Incubations were terminated by washing the cryosections twice in TES buffer ( $25 \mathrm{~mm}, \mathrm{pH} 6.8$ ) including inhibitors to remove excess of free radioligand and finally dipped for one time in distilled water to remove salts. Sections were then immediately wiped off with filter paper and placed into liquid scintillation vials. After addition of $15 \mathrm{ml}$ of scintillation fluid (Quickscint 212, Zinsser Analytic, Frankfurt, Germany), $\left.{ }^{3} \mathrm{H}\right]$ radioactivity was assessed in a Beckman $\beta$-scintillation counter. Specific binding was calculated as the difference between total and non-specific binding.

\section{Receptor Autoradiography}

High-resolution receptor micro-autoradiography was carried out as described by Schremmer-Danninger et al. (1995). For visualisation of ligand binding on cryostat section processed tissue, sections were dried and vapour fixed with paraformaldehyde $\left(2 \mathrm{~h}, 80^{\circ} \mathrm{C}\right)$, defatted and exposed to emulsion coated cover slips for approximately 8 weeks. Developed emulsion-autoradiographs were scanned by a TV camera (Bosch TVK 920, Plumbicon, Darmstadt, Germany) and digitised in the frame grabber Matrox MVP-AT/NP of the PC-based image analyser SAMBA (TITN, Grenoble, France). Areas of interest were selected interactively by the examiner and after definition of the threshold, different parameters were evaluated. The system assessed the number of pixels corresponding to a selected area on the level of the cryostat section. The area of the particle was quantified, and the area of all the particles within the predefined area was given as a percent of the total area.

\section{Carboxypeptidase M Assay}

Carboxypeptidase $M$ activity was evaluated according to the method of Tan et al. (1995). The enzyme activity was evaluated in duplicate determinations in tissue homogenates from control, ischaemic and ischaemia/reperfusion rat pancreas. The mean \pm 
SEM of three representative experiments is shown. The assay is based on the fluorescent substrate dansyl-Ala-Arg, and utilises the ability to extract the product, dansyl-Ala, into chloroform while the remaining substrate stays in the aqueous phase at acid $\mathrm{pH}$. The fluorescence was measured at $340 \mathrm{~nm}$ excitation wavelength and $495 \mathrm{~nm}$ emission.

\section{Immunocytochemistry}

Immunoperoxidase Slides with tissue sections were placed on a heating mantle until the wax melted, and then dewaxed in xylene. Tissues were rehydrated through a series of increasingly dilute ethanol solutions, and placed in distilled water as the final rehydrant. Between the $90 \%$ and $70 \%$ ethanol hydration steps, tissue has to be immersed in absolute methanol for 25 min to quench endogenous peroxidase activity. Moderate boiling in $0.01 \mathrm{~m} \mathrm{Na}$-citrate buffer ( $\mathrm{pH}$ 6.0) for $2 \mathrm{~min}$ in a microwave oven at $80^{\circ} \mathrm{C}$ follows for fixation. Then the tissue is allowed to cool to room temperature $(\mathrm{RT})$ and placed again in distilled water. Before incubating in $10 \% \mathrm{H}_{2} \mathrm{O}_{2} / 95 \%$ methanol (v/v) for 20 min at RT to quench endogenous peroxidases a second time, the tissue has to be washed one time in $0.01 \mathrm{~m}$ phosphate buffered saline $(\mathrm{pH} 7.4) / 1 \%$ bovine serum albumin (v/v) to reduce non-specific binding and afterward two times in $0.01 \mathrm{M}$ phosphate buffered saline ( $\mathrm{pH}$ 7.4). The incubation with the first antibody, diluted in maleic acid $/ 10 \%$ milk-blocker in PBS (Boehringer), takes place overnight at $4{ }^{\circ} \mathrm{C}$ in a humidified chamber. After two washing steps with $0.01 \mathrm{M}$ phosphate buffered saline $(\mathrm{pH} 7.4)$ the tissue on the slides is treated with the peroxidase-anti-peroxiodase (PAP) streptavidin-biotin conjugated system (LSAB K0690, DAKO, Hamburg, Germany) for 20 min each, with phosphate buffered saline ( $\mathrm{pH}$ 7.4) wash steps in between. The labelled antibody bound to the PAP immuno-enzyme complex is visualised by incubating the liquid diaminobenzidine (DAB) precipitant (K3468, DAKO) up to $4 \mathrm{~min}$ in the dark. Tissue is counterstained with Mayer's haematoxylin and eosin. Then the tissue is washed in tap water for $5 \mathrm{~min}$, dehydrated through an ethanol series in xylene and mounted in Entellan (Merck, Ismaning, Germany). Results were viewed by conventional light microscopy.

Immunolabelling Controls In order to assess the specificity of the immunolabelling, method, controls were performed in which the primary antibody was replaced by either buffer (PBS) or non-immune serum.

Anti-Kinin-B1 Receptor Antibody This antibody was kindly provided by Prof. Müller-Esterl and is a mixture of antibodies (AS 367-75) directed to various specific sequences of the human $\mathrm{B} 1$ receptor raised in rabbits, and was used at a dilution of $1 / 800$. This antibody also reacts specifically with murine tissue as the genomic sequences of human, mouse, rabbit and canine kinin $\mathrm{B} 1$ receptors show homology that varies from $72-76 \%$ (Hess et al., 1996). As secondary antibody the appropriate antispecies antibody lgG was used as the sandwich antibody.

\section{Statistics}

All data are shown as mean \pm SEM. Friedman analysis of variance in ranks and Student-Newman-Keul Test were used to show significant differences between the groups. Differences were considered significant at $p<0.05$.

\section{Acknowledgements}

Antagonists were kindly provided by John C. Cheronis, Cortech, Inc., Denver, USA. The authors would also like to thank Prof.
Werner Müller-Esterl, Johann-Wolfgang-Goethe-Universtity, Frankfurt, Germany, for kinin-receptor antibodies. The Sonderforschungsbereich 469 of the Ludwig-Maximilians-University Munich, Germany, the International Office Research Center (KFA), Jülich, Germany, the National Research Foundation of South Africa and Technikon-Natal, Durban, South Africa, supported this work.

\section{References}

Ahluwalia, A., and Perretti, M. (1996). Involvement of bradykininB1-receptors in the polymorphonuclear leukocyte accumulation induced by IL-1 $\beta$ in vivo in the mouse. J. Immunol. 156, $269-274$.

Asano, M., Hatori, C., Inamura, N., Sawai, H., Hirosumi, J., Fujiwara, T., and Nakahara, K. (1997). Effects of a nonpeptide bradykinin-B2-receptor antagonist, FR167344, on different in vivo animal models of inflammation. Br. J. Pharmacol. 122, $1436-1440$.

Austin, C.E., Faussner, A., Robinson, H.E., Chakravarty, S., Kyle, D., Bathon, J.M., and Proud, D. (1997). Stable expression of the human kinin-B1-receptor in Chinese hamster ovary cells; characterisation of ligand binding and effector pathways. J. Biol. Chem. 272, 11420-11425.

Bassi, D., Kollias, N., Fernandez del Castillo, D., Foitzik, T., Warshaw, A.L., and Rattner, D.W. (1994). Impairment of pancreatic microcirculation correlates with the severity of acute experimental pancreatitis. J. Am. Coll. Surg. 179, 257-263.

Bhoola, K.D., Ramsaroop, R., Plendl, J., Cassim, B., Dlamini, Z., and Naicker, S. (2001). Kallikrein and kinin receptor expression in inflammation and cancer. Biol. Chem. 382, 7789.

Bhoola, K.D., Figueroa, C.D., and Worthy, K. (1992). Bioregulation of kinins, kallikreins, kininogens and kininases. Pharmacol. Rev. 44, 1-80.

Bloechle, C., Kusterer, K., Kuehn, R.M., Schneider, C., Knoefel, W.T., and Izbicki, J.R. (1998). Inhibition of bradykinin-B2-receptor preserves microcirculation in experimental pancreatitis in rats. Am. J. Physiol. 274, G42-G51.

Carl, V.S., Moore, E.E., Moore, F.A., and Whalley, E.T. (1996). Involvement of bradykinin B1 and B2 receptors in human PMN elastase release and increase in endothelial cell monolayer permeability. Immunopharmacology 33, 325-329.

Closa, D., Hotter, G., Prats, N., Gelpi, E., and Rosello-Catafau, J. (1995). A bradykinin antagonist inhibited nitric oxide generation and thromboxane biosynthesis in acute pancreatitis. Prostaglandins 49, $285-294$.

Dendorfer, A., Hauser, W., Falias, D., and Dominiak, P. (1996). Bradykinin increases catecholamine release via $\mathrm{B} 2$ receptors. Pflüger's Arch. 432 (Suppl. 3), R99-R106.

Griesbacher, T., Tiran, B., and Lembeck, F. (1993). Pathological events in experimental acute pancreatitis prevented by the bradykinin antagonist, Hoe 140. Br. J. Pharmacol. 108, 405411.

Griesbacher, T., Kolbitsch, C., Tiran, B., and Lembeck, F. (1995). Effects of the bradykinin antagonist, icatibant (Hoe 140), on pancreas and liver functions during and after caerulein-induced pancreatitis in rats. Naunyn-Schmiedeberg's Arch. Pharmacol. 352, 557-564.

Hall, J.M. (1997). Bradykinin receptors. Gen. Pharmacol. 28, $1-6$.

Hess, J.F., Derrick, A.W., MacNeil, T., and Borkowski, J.A. (1996). The agonist selectivity of a mouse B1 bradykinin receptor differs from human and rabbit B1 receptor. Immunopharmacology 33, 1-8. 
Hirata, M., Hayashi, I., Yoshimura, K., Ishii, K., Soma, K., Ohwada, T., Kakita, A., and Majima, M. (2002). Blockade of bradykinin $\mathrm{B}(2)$ receptor suppresses acute pancreatitis induced by obstruction of the pancreaticobiliary duct in rats. $\mathrm{Br}$. J. Pharmacol. 135, 29-36.

Hoffmann, T.F., Leiderer, R., Waldner, H., Arbogast, S., and Messmer, K. (1995). Ischemia reperfusion of the pancreas: a new in vivo model for acute pancreatitis in rats. Res. Exp. Med. 195, 125-144.

Hoffmann, T.F., Steinbauer, M., Waldner, H., and Messmer, K. (1996a). Exogenous bradykinin enhances ischemia/reperfusion injury of pancreas in rats. J. Surg. Res. 62, 144-151.

Hoffmann, T.F., Waldner, H., and Messmer, K. (1996b). The bradykinin antagonist CP-0597 can limit the progression of postischemic pancreatitis. Immunopharmacology 33, 243246.

Hoffmann, T.F., Leiderer, R., Waldner, H., and Messmer, K. (1996c). Bradykinin antagonists HOE-140 and CP-0597 diminish microcirculatory injury after ischaemia-reperfusion of the pancreas in rats. Br. J. Surg. 83, 189-195.

Hoffmann, T.F., Leiderer, R., Harris, A.G., and Messmer, K. (1997). Ischemia and reperfusion in pancreas. Microsc. Res. Tech. 37, 557-571.

Kanbe, T., Naruse, S., Kitagawa, M., Nakae, Y., and Hayakawa, T. (1996). Effects of a bradykinin receptor antagonist (HOE140) on taurocholate-induced acute pancreatitis in rats. Pancreas 13, 283-288.

Klar, E., Endrich, B., and Messmer, K. (1990). Microcirculation of the pancreas. A quantitative study of physiology and changes in pancreatitis. Int. J. Microcirc. Clin. Exp. 9, 85-101.

Marceau, F., Larrivee, J.F., Saint Jacques, E., and Bachvarov, D.R. (1974). The kinin-B1-receptor: an inducible G protein coupled receptor. Can. J. Physiol. Pharmacol. 75, 725-730.

Mazenot, C., Loufrani, L., Henrion, D., Ribuot, C., Müller-Esterl, W., and Godin-Ribuot, D. (2001). Endothelial kinin-B1-receptors are induced by myocardial ischaemia-reperfusion in the rabbit. J. Physiol. 530, 68-78.

Nwator, I., and Whalley, E.T. (1989). Angiotensin converting en- zyme inhibitors and expression of des-Arg'-bradykinin (kinin $\mathrm{B}_{1}$ ) receptors in vivo. Eur. J. Pharmacol. 160, 125-132.

Pruneau, D., Luccarini, J.M., Robert, C., and Belichard, P. (1994). Induction of kinin B1 receptor-dependent vasoconstriction following balloon catheter injury to the rabbit carotid artery. Br. J. Pharmacol. 111, 1029-1034.

Regoli, D., Barabe, J., and Park, W.K. (1977). Receptors for bradykinin in rabbit aortae. Can. J. Physiol. Pharmacol. 55, $855-867$.

Satake, K., Ha, S.S., and Hiura, A. (1996). Effects of bradykinin receptor antagonist on the release of $\beta$-endorphin and bradykinin and on hemodynamic changes in a canine model of experimental acute pancreatitis. Pancreas 12, 92-97.

Schmid-Schoenbein, G.W., Zwiefach, B.W., and Kovalcheck, S. (1997). The application of stereological principles to morphometry of the microcirculation in different tissues. Microvasc. Res. 14, 303-317.

Schremmer-Danninger, E., Heinz-Erian, P., Toepfer-Petersen, E., and Roscher, A.A. (1995). Autoradiographic localization and characterization of bradykinin receptors in human skin. Eur. J. Pharmacol. 283, 207-216.

Schremmer-Danninger, E., Oeffner, A., Siebeck, M., and Roscher, A.A. (1998). B1 bradykinin receptors and carboxypeptidase $M$ are both upregulated in the aorta of pigs after LPS infusion. Biochem. Biophys. Res. Commun. 243, 246-252.

Siebeck, M., Spannagl, E., Schorr, M., Stumpf, B., Fritz, H., Whalley, E.T., and Cheronis, J.C. (1996). Effect of combined B1 and B2 kinin receptor blockade in porcine endotoxin shock. Immunopharmacology 33, 81-84.

Tan, F., Deddish, P.A., and Skidgel, R.A. (1995). Human carboxypeptidase M. Methods Enzymol. 248, 663-675.

Yekebas, E., Treede, H., Jochum, M., Gippner-Steppert, C., Bloechle, C., Knoefel, W.T., Scholz, J., Fink, E., and Izbicki, J.R. (2000). Bradykinin B2-receptor antagonism attenuates fatal cardiocirculatory breakdown induced by severe experimental pancreatitis. Crit. Care Med. 28, 1119-1127.

Received January 9, 2003; accepted June 12, 2003 